\title{
A Comparative Study on Compressive Strength of Concrete Mix Containing Plastic, Glass and Rubber Aggregates
}

\author{
Khandaker Samin Atif ${ }^{1}$, Md. Asadullah-Al-Galib ${ }^{1}$, Nabil Ahmed ${ }^{1}$, Nayem Hasan ${ }^{1}$, Saurav Barua $^{2, *}$ \\ ${ }^{1}$ Department of Civil Engineering, Ahsanullah University of Science and Technology, Dhaka, Bangladesh \\ ${ }^{2}$ Department of Civil Engineering, Daffodil International University, Dhaka, Bangladesh
}

\section{Email address:}

saminatif97@gmail.com (K. S. Atif), algalibce@gmail.com (Md. Asadullah-Al-Galib), nabil103504@gmail.com (N. Ahmed), nayemhasan4908@gmail.com (N. Hasan), saurav.ce@diu.edu.bd (S. Barua)

${ }^{*}$ Corresponding author

\section{To cite this article:}

Khandaker Samin Atif, Md. Asadullah-Al-Galib, Nabil Ahmed, Nayem Hasan, Saurav Barua. A Comparative Study on Compressive Strength of Concrete Mix Containing Plastic, Glass and Rubber Aggregates. Advances in Applied Sciences. Vol. 5, No. 4, 2020, pp. 97-102.

doi: $10.11648 /$ j.aas.20200504.11

Received: July 20, 2020; Accepted: July 30, 2020; Published: November 4, 2020

\begin{abstract}
In this study, the behavior of the recycled plastic, glass and rubber tire as partial replacement of coarse aggregate in concrete have been investigated. Polyethylene terephthalate (PET) bottles, one of the waste plastic types, broken glass of bottles and rubber tires are used for these purposes. The reason to choose these to transfer the recycles materials into valuable product and to solve the problem of dumping the tons of plastic waste, broken glass and rickshaw tires. In this study compressive strength of cylinder concrete specimens were carried out at 7 and 28 days curing. Six concrete mixes have been studied, those are-reference specimens with no recycled material (CS0), specimens with 15\% plastic (CSP15), specimens with 15\% (CSR15) and 30\% (CSR30) tire, specimens with 15\% (CSG15) and 30\% (CSG30) glass. Total 24 cylindrical specimen of 8 "x4" were tested for compressive strength. The order of compressive strength was CS0 $>$ CSG30 $>$ CSG15 $>$ CSR15 $>$ CSR30 $>$ CSP 15 . The Study found that compressive strength of concrete mix decreases with the increase of plastic and rubber content. However, compressive strength of concrete increases with the increase of glass content. Plastic material have low bonding with cement in concrete and perform poorly. On contrary, glass works very well with concrete and compressive strength of concrete reduces with the increase of rubber content.
\end{abstract}

Keywords: Waste Plastic, Broken Glass, Rubber Tire, Concrete Compressive Strength, Non-biodegradable Materials

\section{Introduction}

Concrete is widely used construction material around the world. Utilizing waste and recycled materials in concrete mixes draw greater attention to treat and manage solid waste generated through industry and municipal sewer now-a-days. Around $65 \%-85 \%$ of concrete volume contains coarse aggregate and they provide strength, durability, workability and stability. Usually, stone chips, crushed stone and brick chips are used as coarse aggregate in concrete. However, usage of waste materials in concrete along with conventional aggregates can solve waste materials disposal problem and provide lighter weight where low compressive strength concrete can serve the needs. This study aims at examining the effect of recycled plastic, broken glass and rickshaw tire in concrete as coarse aggregate through compressive strength test for the better understanding of the behavior of those recycled materials in concrete mix.

Using recycled coarse aggregate (RCA) can not only reduce environmental problem caused by the conventional aggregate production greatly, but also the disposal problem of the RCA can be solved. Recycling wastes, such as, plastic bottles, broken glasses and rubber tires will lead to reduction in valuable landfill space and savings in natural resources. RCA will also provide other benefits, such as creation of additional business opportunities, saving cost of disposal, saving money for local government and other purchaser, helping local government to meet the goal of reducing disposal etc. However, these can also help to conserve natural materials and to reduce the cost of waste treatment prior to the disposal. 
This research has conducted with the use of recycled aggregates as modification. In terms of the use of recycled aggregates, the percentages of RCA were determined because the strength of concrete would not be obtained by the high percentage of recycled aggregates. The scope of study is about comparison between natural aggregate and RCA for $0 \%, 15 \%$ and $30 \%$ replacement at 7 and 28 days compressive strength. Moreover, this research also focuses on the failure pattern of concrete cylinder containing both natural aggregate and RCA. The state of the art of this study is to provide a comparative study of the partial replacements of coarse aggregate by waste plastic, broken glass and rubber tire in concrete mix in terms of compressive strength and investigate their feasibility.

\section{Literature Review}

Plastic products, waste glass and rubber tire comprise large share of solid waste and cause serious environmental pollution. Plastics have been used in packaging, preservation and distribution of food, industrial and automotive application, transport and delivery materials and so on. Plastic products are non-biodegradable and its large and varying applications contribute to an ever increasing volume in the solid waste stream. Besides, waste broken glass can reduce consumption of fine aggregate and it is cheaper to store than to recycle, as it is expensive for the recycling process. In addition, every year large amount of automobile, cycle and rickshaw tire are discarded and dumped which are not easily biodegradable even after a long period of landfill treatment. As a result, rubber tire cause major environmental challenges in the world.

Gaikwad et al. [1] used waste plastic waste as coarse aggregate in concrete mix and found that compressive strength and workability improved. Usage of plastic as coarse aggregate in concrete mix can reduce landfill cost and save energy [2]. Jaivignesh and Sofi [3] suggested that plastic aggregate in concrete mix reduce concrete strength, because of lack of bonding between cement and plastic aggregate. Up to $10 \%$ replacement of coarse aggregate by shredded plastic product can improve compressive and tensile strength of concrete [4].

Scanning electron microscopy (SEM) analysis showed that silica in glass provides better bonding in concrete mix [5]. Olofinnade et al. [6] suggested waste glass can be used up to
$25 \%$ as replacement of coarse aggregate in concrete mix and can be used as light weight concrete. Coarse glass aggregate have good compressive strength and provide adequate bond strength [7]. Crushed glass aggregate reduce strength in concrete due to low adhesion with cement and suggested to use it as footpath construction materials [8].

Záleská et al. [9] suggested that rubber type aggregate in concrete can improve thermal insulation as well as have good mechanical strength. Rebound hammer test showed that the combination of tire rubber and fly ash in concrete can provide adequate compressive strength [10]. David et al. [11] used mixture of crumbled tire and recycled asphalt to build concrete pavement. They found that the concrete pavement have similar performance like natural aggregate built pavement, on the other hand, reduce material cost significantly.

All of the above studies investigate performance of recycle waste plastic, glass and rubber materials as the partial replacement of coarse aggregate separately. Our research provides a comparative study among the usage of those recycle waste materials in concrete mix. To our best knowledge, no prior study have been conducted considering such comparisons.

\section{Experimental Procedure}

\subsection{Materials}

The materials were used in the test program include ordinary Portland cement, natural coarse aggregate, sand, water, recycled plastic, broken glass and recycled tire rubber. The cement met the requirements of ASTM C150 [12] specifications (Table 1). Tap water, potable without any salts or chemicals was used in all concrete mixtures and in the curing of specimens. The water-cement ratio was 0.45 . Locally available crushed limestone coarse aggregate was used in this study. The nominal size of coarse aggregate was $19 \mathrm{~mm}$ (Table 2). Naturally available Sylhet sand was used and size range $0.075 \mathrm{~mm}-4.75 \mathrm{~mm}$. Moisture content of coarse and fine aggregate was done according to ASTM C566 [13]. The moisture content was $1 \%$ for all types. ASTM C136 [14] procedure was used to determine the gradation of coarse and fine aggregate, obtained Fineness Modulus (FM) was 3.36 (Table 3).

Table 1. Properties of cement used in the concrete mix.

\begin{tabular}{|c|c|c|}
\hline Test & Results & ASTM C 150 Requirements \\
\hline \multicolumn{3}{|l|}{ Setting Time (vicat test) } \\
\hline Initial & $130 \mathrm{~min}$ & $>60 \mathrm{~min}$ \\
\hline \multicolumn{3}{|c|}{ Compressive Strength (MPa) } \\
\hline 3 days & 16.47 & Min. 12 \\
\hline 7 days & 29.81 & Min. 19 \\
\hline 28 days & 44.03 & --------- \\
\hline Fineness $\left(\mathrm{cm}^{2} / \mathrm{gm}\right)$ & 3223.6 & Min. 2800 \\
\hline Normal Consistency (\%) & 25.5 & --------- \\
\hline
\end{tabular}


Table 2. Properties of Coarse aggregates used in concrete mix.

\begin{tabular}{ll}
\hline Coarse Aggregate size & $19 \mathrm{~mm}$ \\
Dry bulk density $\left(\mathrm{kg} / \mathrm{m}^{3}\right)$ & 1440 \\
Absorption $(\%)$ & 4.2 \\
Specific gravity of PET aggregate & 1 \\
Specific gravity of rubber tire & 1.18 \\
Specific gravity of broken glass & 2.5 \\
\hline
\end{tabular}

Table 3. Sieve Analysis of Aggregates.

\begin{tabular}{|c|c|c|c|c|c|}
\hline Sieve No. & Sieve Opening (mm) & Material Retained (gm) & $\%$ Material Retained & Cumulative\% Retained & $\%$ Finer \\
\hline $3 / 2$ in & 37.5 & 0 & 0 & 0 & 100 \\
\hline $3 / 4$ in & 19 & 510 & 33.33 & 33.33 & 66.67 \\
\hline $1 / 2$ in & 12.5 & 370 & 24.18 & 57.51 & 42.49 \\
\hline $3 / 8$ in & 9.5 & 100 & 6.5 & 64.01 & 35.99 \\
\hline \#4 & 4.75 & 30 & 1.96 & 65.97 & 34.03 \\
\hline \#8 & 2.36 & 40 & 2.61 & 68.58 & 31.42 \\
\hline \#16 & 1.18 & 220 & 14.38 & 82.96 & 17.04 \\
\hline$\# 30$ & 0.6 & 170 & 11.11 & 94.07 & 5.93 \\
\hline \#50 & 0.3 & 60 & 3.92 & 97.99 & 2.01 \\
\hline$\# 100$ & 0.15 & 20 & 1.3 & 99.29 & 0.71 \\
\hline Pan & & 10 & 0.71 & 100 & 0.06 \\
\hline Total & & 1530 & 100 & & \\
\hline
\end{tabular}

Polyethylene terephthalate (PET) bottles, collected from a disposal area was shredded and crushed in a plastic recycled plant to small fraction and washed to remove the foreign particles as well as oily texture (Figure 1). The rubber tire used in this study was culled from scrap dealer, then rubber tires were cut mechanically into a size less than $25 \mathrm{~mm}$. Ground rubber (19mm size) was taken which had been found by sieving. The retained rubber in $3 / 4$ inch sieve was used to carry out the test. The sample glass was culled from local glass shop. The collected glass was then broken manually and then taken the sample as aggregate which was retained in $3 / 4$ inch sieve while sieving.

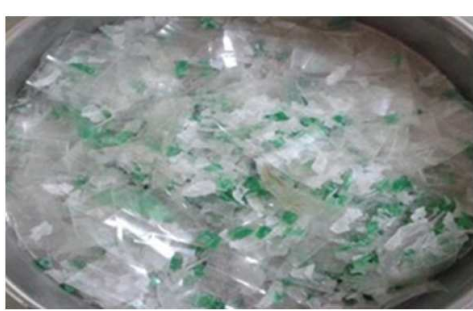

(a)

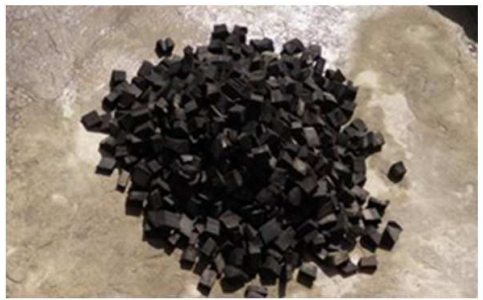

(b)

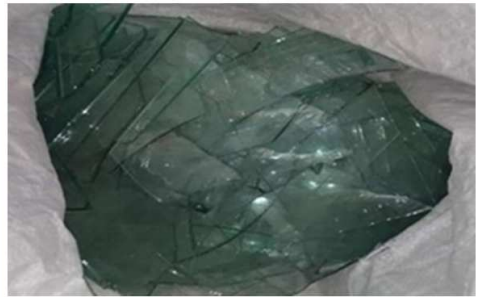

(c)

Figure 1. Partial replaced material of Coarse aggregate (a) Shredded PET Bottles sample (b) Waste rubber tire particles cut into coarse aggregates size (c) Broken glass.

\subsection{Mixing, Casting and Curing}

In this study, the mix proportions were prepared according to ACI 211.1. Six concrete mixes were prepared in this study with compressive strength B300. One concrete mix contains only natural aggregate as reference and five concrete mixes contain PET aggregate by replacing $15 \%$, glass aggregate by replacing $15 \%$ and $30 \%$, ground tire aggregate by replacing $15 \%$ and $30 \%$ in volume of natural aggregate by an equal volume of PET, glass, and rubber tire aggregate. Grades of Concrete was M 15 and ratio of cement: fine aggregate: coarse aggregate were 1:2:4. Dimension of each cylinder specimen was $8 " \times 4 "$. Two samples for every concrete mix were prepared to be tested for compressive strength after 7 and 28 days curing under water. The samples were immersed in water tank filled with fresh water at room temperature for the above mentioned days in the laboratory. Concrete containing artificial aggregate has to comply with the same requirements as concrete made with natural aggregate. The mix operation of concrete for all samples was taken place in a conventional blade-type mixer according to ASTM C192 [15]. Total 6 type specimens were prepared which are designated as shown in Table 4.

Table 4. Designation of concrete mix specimens

\begin{tabular}{ll}
\hline Designation & Details \\
\hline CS0 & Reference Concrete specimen (Zero\% recycled aggregate) \\
CSP15 & Replaced $15 \%$ of Natural Aggregate by PET aggregate (by Volume) \\
CSR15 & Replaced $15 \%$ of Natural Aggregate by rubber aggregate (by Volume) \\
CSR30 & Replaced $30 \%$ of Natural Aggregate by rubber aggregate (by Volume) \\
CSG15 & Replaced $15 \%$ of Natural Aggregate by glass aggregate (by Volume) \\
CSG30 & Replaced $30 \%$ of Natural Aggregate by glass aggregate (by Volume) \\
\hline
\end{tabular}




\subsection{Test Methods}

24 cylindrical specimens of size 8 inch $\times 4$ inch were casted for conducting compressive strength test. The cylinder was filled with fresh concrete in two layers and each layer was tamped 25 times with a tamping rod. Immediately after prepared cylinder, the specimens were covered to prevent water evaporation. Universal testing machine (UTM) was used to measure compressive strength of concrete specimens. The compressive strength test was based on ASTM C109 and was tested at the end of the 7 and 28 days of curing. The compressive strength of any mix was taken as the average strength of two cylinders. After 24 hours, cylinder extracted from forms and stored in water (curing phase) up to the time of test. Before testing, specimens were air dried for 10 to 15 minutes. The compressive strength of the specimen, $\sigma_{\text {comp }}$ (in $\mathrm{MPa}$ ), is calculated by dividing the maximum load carried by the cylinder specimen during the test by the cross sectional area of the specimen.

\section{Results and Discussion}

\subsection{Failure Pattern and Bonding}

Failure pattern of cylinders were observed as per the ASTM specification C39/ C39M and C192/ C192M. Adhesion force

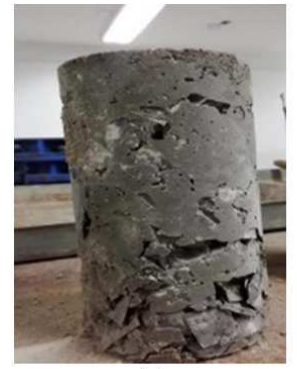

(a)

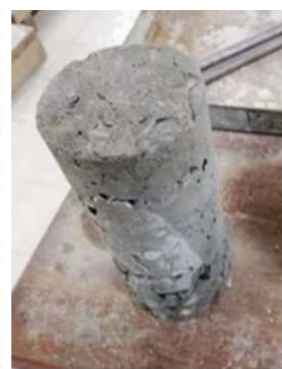

(b)

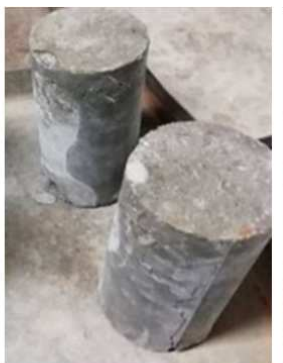

(c)

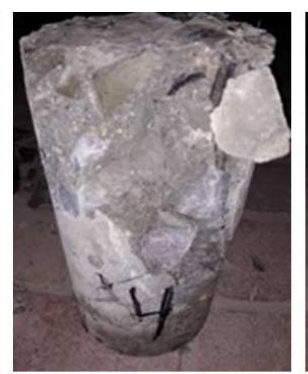

(d)

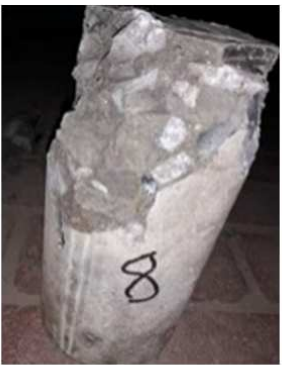

(e)

between mortar and plastic was very poor in CSP15 specimens (Figure 2). The outer surface was not as smooth as the reference specimen CSO. The failure pattern of the specimen of $15 \%$ plastic with mortar (CSP15), found no similarities with the standard fracture type, having poor adhesion of plastic with mortar and those are not acceptable. The bonding between 15\% rubber with mortar (CSR15) was far better than that of the previous one. CSR 15 specimens have side factures at top or bottoms (Type 5). Aggregate is showing broken in the fracture. However, the more increase of rubber percentage (CSR30), the more deviates from its reference specimen CS0. The CSR30 specimens have reasonably well-formed cones on both ends, less than 1 in. (25 $\mathrm{mm}$ ) of cracking through caps (Type 1). Neither of the two categories is as good as the specimen comprised glass with mortar (CSG15, CSG30). The adhesion force was acceptable and outer surface was rough in CSG15, CSG30 specimens and could be assimilated with reference specimen. CSG30 specimens have diagonal fracture with no cracking through ends, which can be tapped with hammer produce distinguishable sound (Type 4). The specimens comprised of $15 \%$ glass with mortar (CSG15) and cannot be identified similarities with the standard fracture type. Mortar binding is fully broken in the failure of CSG15 (Figure 2).

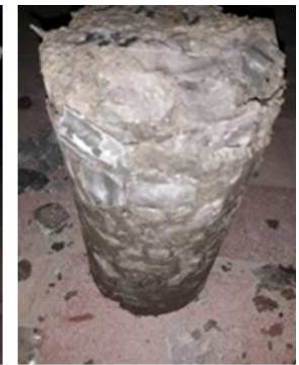

(f)

Figure 2. Photographs of specimens (a) CSP15, (b) CSR15, (c) CSG30, (d) Failure of CSR30 (Type 1) at crushing, (e) Failure of CSG15 (Type 4) at crushing and (f) Failure of CSR15 (Type 5) at crushing.

\subsection{Compressive Strength}

Compressive strength determines the performance of the RCC materials during service conditions. It is an effective way of measuring how much load a surface or material can sustain under compression. Table 5 shows the compressive strength obtained from different test specimens.

Table 5. Compressive strength (Mpa) obtained from various concrete mix specimens.

\begin{tabular}{|c|c|c|c|c|c|c|}
\hline \multirow{3}{*}{ Specimen type } & \multicolumn{6}{|c|}{ Compressive strength (Mpa) } \\
\hline & \multicolumn{3}{|l|}{7 days } & \multicolumn{3}{|l|}{28 days } \\
\hline & Specimen 1 & Specimen 2 & Average & Specimen 1 & Specimen 2 & Average \\
\hline CS0 & 10.88 & 9.85 & 10.36 & 16.56 & 16.10 & 16.33 \\
\hline CSP15 & 2.78 & 3.41 & 3.09 & 2.00 & 4.20 & 3.10 \\
\hline CSR15 & 5.42 & 5.21 & 5.32 & 7.04 & 7.28 & 7.16 \\
\hline CSR30 & 3.06 & 2.77 & 2.92 & 4.43 & 5.24 & 4.84 \\
\hline CSG15 & 5.35 & 4.93 & 5.14 & 9.92 & 6.23 & 8.07 \\
\hline CSG30 & 6.67 & 6.72 & 6.69 & 11.13 & 10.93 & 11.03 \\
\hline
\end{tabular}




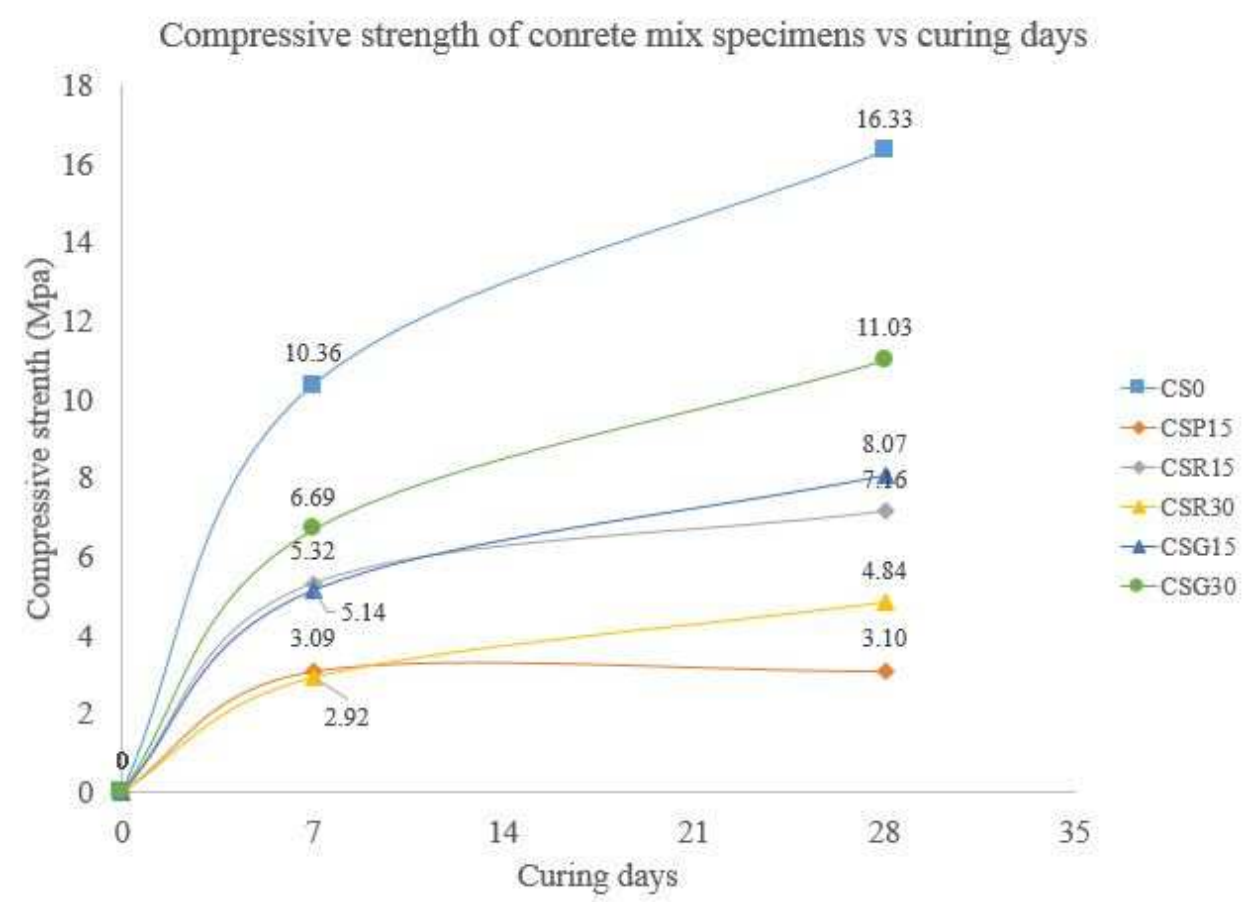

Figure 3. Compressive strength of various concrete specimens under different curing periods.

$\%$ Comparison of compressive strength of different concrete mix with respect to reference specimen (CSO)

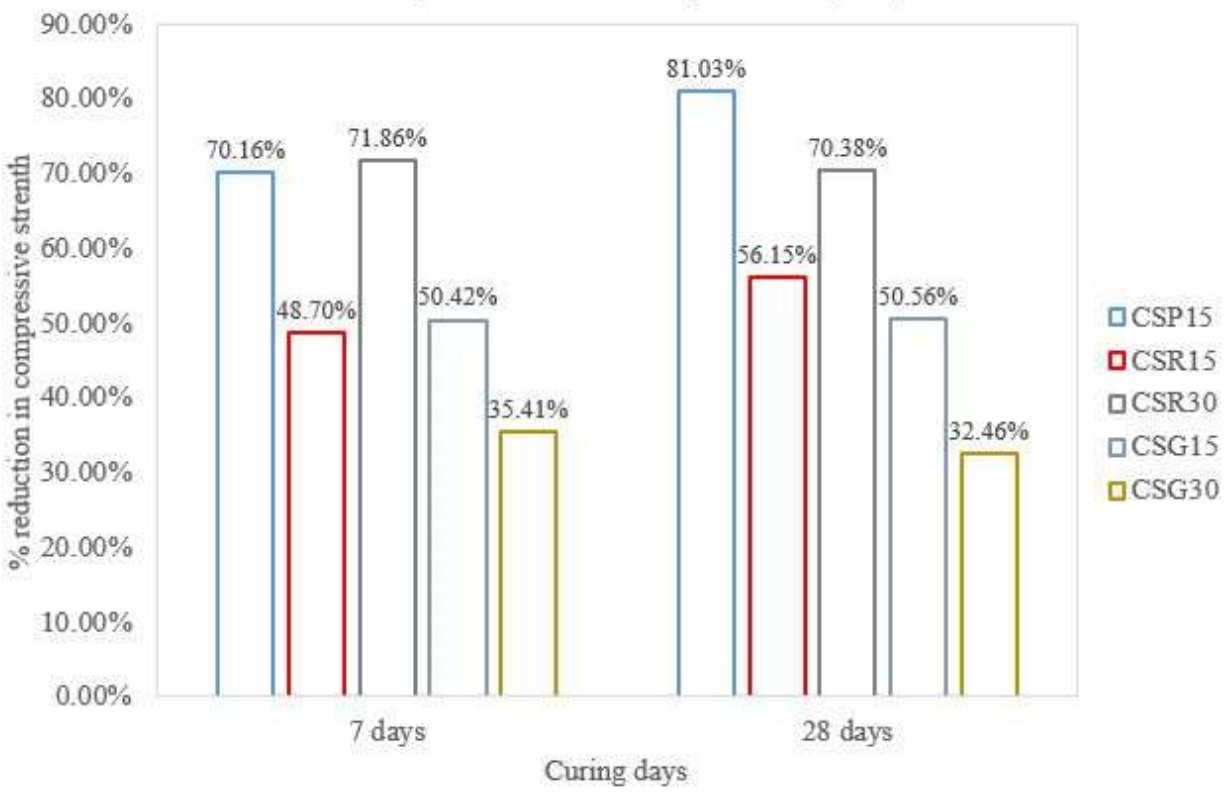

Figure 4. \% reduction of compressive different concrete specimens with respect to reference concrete mix where no recycled aggregate used (CSO).

The test results show that addition of RCA that we used i.e. plastic chips, tyre \& broken glass resulting to significant reduction in compressive strength compared to conventional concrete at 7 and 28 days (Figure 3). From the scenario of this graph, one can conclude that rapid in strength gain takes place up to its 7 days of curing later on its gaining rate becomes slower. The compressive strength of $15 \%$ plastic has increased from 3.09 $\mathrm{MPa}$ to $3.1 \mathrm{MPa}$ from 7 days to 28 days respectively which is way much smaller increases. This increase in the content of plastic aggregate reduces the density of concrete, the reduction is greater with bigger and flakier particles of plastic aggregate.

The compressive strength values gradually decrease from $15 \%$ to $30 \%$ replacement increase of rubber tire in concrete. The reduction of compressive strength in specimens is due to the appeared of bleeding of mixing water from the freshly mixed concrete. The results of compressive strength loss of concrete made using broken glass as coarse aggregate replacement are $50.56 \%$ (CSG15) and 32.46\% (CSG30), which are minimum under 28 days curing. Broken glass works better than tire and plastic as a replacement of coarse 
aggregate. Among the recycle concrete mix, CSG30 have highest compressive strength. Increased in strength may be due to the higher volume of equivalent waste broken glass as compare to natural stone chips since former is lighter than the later. At 28 days, compressive strength follows order as- $\mathrm{CS} 0>$ CSG30 $>$ CSG15 $>$ CSR15 $>$ CSR30 $>$ CSP15.

\section{Conclusions}

Plastic materials are weak in bonding with cement. However, uses of plastic is eco-friendly which can bring down the global carbon footprint quite effectively. Partial coarse aggregates replacement in concrete mix by tire i.e. rubber leads to a reduction in the density of the final product, because the specific gravity of rubber used was less than that of coarse aggregates. However, increasing proportion of rubber content can decrease compressive strength of concrete. The strength reduction may be attributed to two reasons. First, because the rubber tire particles are much softer (elastically deformable) than the surrounding mineral materials, and on loading, cracks are initiated quickly around the rubber particles in the mix, which accelerates the failure of the rubber-cement matrix. Second, soft rubber particles may behave as voids in the concrete mix, due to the lack of adhesion between the rubber particles and the cement paste. Waste broken glass it acts as a source of waste disposal which can be used in construction industry. In addition to that waste broken glass will reduce demand for additional waste disposal infrastructure and decrease the load on existing landfills and incinerators.

More research is required on influencing factors such as the treated plastic, tire and broken glass as aggregates, shapes and sizes of aggregates, favorable mix compositions of concrete, curing condition, etc. to grow confidence on the use of these recycle aggregates in concrete. It is suggested that for the glass concrete specimens, the trend of the increased compressive strength with the increase of glass percentage. Therefore, the concrete containing crushed glass as a partial replacement of natural gravel could achieve a comparable strength with the normal specimens. Electronic waste, coconut shell can also be used as recycled coarse aggregate according to some researches. Plastic, tire, broken glass can be used in those building members which carry light load.

\section{Acknowledgements}

The research is supported by the Department of Civil Engineering, Ahsanullah University of Engineering and Technology (AUST), Bangladesh.

\section{References}

[1] Gaikwad, M. N., Shubham, A. G., Gannesh, Y. H., Mangesh, M. K., \& Pratik, A. G. (2018). Experimental study on plastic waste as a course aggregate for structural concrete. International Journal on Recent and Innovation Trends in Computing and Communication, 6 (4), 63-67.
[2] Bt, A. M. (2016). Partial replacement of e-plastic waste as coarse-aggregate in concrete. Procedia Environmental Sciences, $35,731-739$.

[3] Jaivignesh, B., \& Sofi, A. (2017, July). Study on mechanical properties of concrete using plastic waste as an aggregate. In IOP Conference Series: Earth and Environmental Science (Vol. 80, No. 1, p. 012016).

[4] Islam, M. J., Dipta, I. A., \& Rahat, M. (2018). Investigation of recycled poly-ethylene terephthalate (PET) as partial replacement of coarse aggregate in concrete. Journal of Civil Engineering (IEB), 46 (1), 11-20.

[5] Rajagopalan, P., Balaji, V., Unnikrishnan, N., Haq, T. J., \& Bhuvaneshwari, P. (2017, July). Study of Bond Characteristics of Reinforced Waste Glass Aggregate Concrete. In IOP Conf. Series: Earth and Environmental Science.

[6] Olofinnade, O. M., Ndambuki, J. M., Ede, A. N., \& Olukanni, D. O. (2016). Effect of substitution of crushed waste glass as partial replacement for natural fine and coarse aggregate in concrete. In Materials Science Forum (Vol. 866, pp. 58-62). Trans Tech Publications Ltd.

[7] Metawei, H., Elkashif, A. F., Arafa, D., \& Taha, N. A. (2019). Experimental Study on Concrete Made With Waste Glass Aggregates. Al Azhar University Journal.

[8] Mohammadinia, A., Wong, Y. C., Arulrajah, A., \& Horpibulsuk, S. (2019). Strength evaluation of utilizing recycled plastic waste and recycled crushed glass in concrete footpaths. Construction and Building Materials, 197, 489-496.

[9] Záleská, M., Pavlíková, M., Čítek, D., \& Pavlík, Z. (2019, November). Mechanical and thermal properties of light-weight concrete with incorporated waste tire rubber as coarse aggregate. In AIP Conference Proceedings (Vol. 2170, No. 1, p. 020026). AIP Publishing LLC.

[10] Banasode, N. Y. (2017). Investigation Performance by Relatively Substitution of Cement and Coarse Aggregate by Fly ash and Waste Tire Rubber in Concrete. International Research Journal of Engineering and Technology, 4 (10), 1615-1619.

[11] David, T. K., Chandrasegaran, R. S., \& Nair, S. K. (2018, June). Modified pervious concrete containing recycled asphalt pavement and waste tire rubber. In IOP Conference Series: Materials Science and Engineering (Vol. 371, p. 012011). IOP Publishing.

[12] ASTM, (2001). ASTM C150: Standard specification for Portland cement. Philadelphia^ ePA PA: ASTM.

[13] Standard, A. S. T. M., C566 (2013). Standard Test Method for Total Evaporable Moisture Content of Aggregate by Drying. ASTM International, West Conshohocken, PA, 2013, DOI: 10.1520/C0566-13.

[14] ASTM, C. (2006). Standard test method for sieve analysis of fine and coarse aggregates. ASTM C136-06.

[15] ASTM C192. (2016). ASTM C192/C192M-16a standard practice for making and curing concrete test specimens in the laboratory. ASTM Standard Book, 4-9. 